\title{
Maternal selenium status during early gestation and risk for preterm birth
}

\author{
Margaret P. Rayman DPhil, Hennie Wijnen PhD, Huib Vader PhD, Libbe Kooistra PhD, Victor Pop MD PhD
}

\begin{abstract}
Background: Preterm birth occurs in 5\%-13\% of pregnancies. It is a leading cause of perinatal mortality and morbidity and has adverse long-term consequences for the health of the child. Because of the role selenium plays in attenuating inflammation, and because low concentrations of selenium have been found in women with preeclampsia, we hypothesized that low maternal selenium status during early gestation would increase the risk of preterm birth.
\end{abstract}

Methods: White Dutch women with a singleton pregnancy $(n=1197)$ were followed prospectively from 12 weeks' gestation. Women with thyroid disease or type 1 diabetes were excluded. At delivery, 1129 women had complete birth-outcome data. Serum concentrations of selenium were measured during the 12th week of pregnancy. Deliveries were classified as preterm or term, and preterm births were subcategorized as iatrogenic, spontaneous or the result of premature rupture of the membranes.

Results: Of the 60 women (5.3\%) who had a preterm birth, 21 had premature rupture of the membranes and 13 had preeclampsia. The serum selenium concentration at 12 weeks' gestation was significantly lower among women who had a preterm birth than among those who delivered at term (mean 0.96 [standard deviation (SD) 0.14] $\mu \mathrm{mol} / \mathrm{L}$ v. 1.02 [SD $0.13] \mu \mathrm{mol} / \mathrm{L} ; t=2.9, p=0.001)$. Women were grouped by quartile of serum selenium concentration at 12 weeks' gestation. The number of women who had a preterm birth significantly differed by quartile $\left(\chi^{2}=8.01,3\right.$ degrees of freedom], $p<0.05)$. Women in the lowest quartile of serum selenium had twice the risk of preterm birth as women in the upper three quartiles, even after adjustment for the occurrence of preeclampsia (adjusted odds ratio 2.18, 95\% confidence interval 1.25-3.77).

Interpretation: Having low serum selenium at the end of the first trimester was related to preterm birth and was independent of the mother having preeclampsia. Low maternal selenium status during early gestation may increase the risk of preterm premature rupture of the membranes, which is a major cause of preterm birth.
$\mathrm{P}$ reterm birth occurs in 5\%-13\% of pregnancies and is a major public health concern worldwide. ${ }^{1}$ Preterm birth, defined as delivery before 37 weeks' gestation, is the leading cause of perinatal mortality and morbidity. ${ }^{2}$ Shortand long-term consequences to the health of the child include cerebral palsy, respiratory distress syndrome, neurodevelopmental impairment, learning difficulties and behavioural problems. ${ }^{2}$ Despite substantial efforts to explain the mechanisms involved, the incidence of preterm birth is on the rise. For example, in the United States, the incidence increased from $9.5 \%$ in 1981 to $12.7 \%$ in 2005. ${ }^{1}$ Consequently, it is important to identify factors that may contribute to preterm birth, particularly those factors that are preventable.

Maternal risk factors for preterm birth include a previous preterm delivery, black race, low socioeconomic status, poor nutrition or becoming pregnant soon after a previous delivery. ${ }^{1}$ Risk factors for preterm birth during gestation include multiple-gestation pregnancy and an intrauterine infection that triggers an inflammatory response. ${ }^{1,3}$ Endocrine conditions such as diabetes and dysfunction of the thyroid have also been associated with preterm birth, sometimes linked to preterm premature rupture of the membranes. ${ }^{4.5}$

The trace mineral selenium, available from food (though to a greater or lesser extent according to region), can interact with a number of these risk factors. ${ }^{6-9}$ It has been implicated in pregnancy outcome, ${ }^{9-12}$ and it plays a role in the immune response and the body's resistance to infection. ${ }^{6}$ Enzymes containing the mineral, selenoenzymes, can attenuate the excessive
Competing interests: Margaret Rayman has received payment from Pharma Nord and Alltech for lectures. No other competing interests were declared.

This article has been peer reviewed.

Correspondence to: Margaret P. Rayman, m.rayman@surrey.ac.uk

CMAJ 2011. DOI:10.1503 /cmaj.101095 
inflammatory response associated with adverse pregnancy outcomes, downregulating the expression of pro-inflammatory genes.$^{6-8} \mathrm{~A}$ polymorphism in the gene encoding the selenoprotein SEPS1 has been shown to affect the risk of preeclampsia, a condition that has a strong inflammatory component that is an important cause of preterm birth. ${ }^{8}$ In addition, low selenium status has been identified in women with preeclampsia. $^{12}$

We hypothesized that low maternal selenium status (as measured by low serum selenium concentration early in gestation would be associated with preterm birth. Previous small studies have compared plasma selenium and plasma/ erythrocyte glutathione peroxidase in mothers and their babies during both term and preterm deliveries. Although lower values have often been found in mothers who had their babies preterm than in mothers who had their babies at term, the findings were inconsistent. ${ }^{13-15} \mathrm{We}$ did a prospective study to assess selenium status in a large cohort of pregnant women who were followed from early gestation to delivery.

\section{Methods}

\section{Participants and samples}

The study was done in the city of Eindhoven, the Netherlands. Residents of the Netherlands are known to have relatively low selenium status. ${ }^{16}$ Over a period of two years, we identified 1702 women who could potentially participate in the study. To avoid language barriers and possible confounding by ethnicity, only white Dutch women $(n=1507)$ were included in the study, and $79 \%$ of them $(n=1197)$ gave their consent. The nonrespondents did not significantly differ from the respondents in terms of age, parity or level of education (data not shown). Women with known thyroid disease $(n=21)$ or type 1 diabetes $(n=5)$, women who had become pregnant after hormonal stimulation $(n=8)$ and women with a multiple-gestation pregnancy $(n=8)$ were excluded from the study. A total of 1155 eligible women were followed throughout their pregnancies.

Blood samples were drawn at 12 weeks' gestation. Demographic data (age, income, marital status and level of education), lifestyle characteristics (smoking status, consumption of alcohol and body mass index) and previous obstetric history were recorded. Complete data were missing for 26 women, so data for 1129 women were used in the analysis.

This study was approved by the Medical Ethics Committee of Máxima Medical Centre in Eindhoven-Veldhoven.

\section{Outcomes}

Gestational age was assessed by calculating from the date of the last menstrual cycle and from an ultrasound scan during what was presumed to be the 12th week of pregnancy. If a discrepancy of more than seven days was seen between these two measurements, a second ultrasound scan was done within two weeks to reassess gestational age. Preterm birth was defined according to the World Health Organization (WHO) definition (birth before 37 weeks' gestation). Preterm births were subcategorized as follows: ${ }^{1}$ iatrogenic, or delivery for maternal or fetal indications (e.g., preeclampsia or intrauterine growth restriction), in which labour was induced or the infant was delivered by prelabour cesarean section; idiopathic, or spontaneous preterm labor with intact membranes; and preterm premature rupture of the membranes with either a vaginal or a cesarean birth.

Serum concentrations of selenium were measured at 12 weeks' gestation by mass spectrometry with inductively coupled plasma using an Elan 6100 Dynamic Reaction Cell Plus (PerkinElmer, Waltham, Massachusetts). The amount of selenium 78 was measured using methane gas $(0.5 \mathrm{~mL} / \mathrm{min})$ in the dynamic reaction cell to remove the argon dimer from the background. Butanol was used to increase the sensitivity of the signal. ${ }^{17}$ The within-run coefficient of variation was $2.1 \%-2.6 \%$ and the between-run coefficient of variation was 3.1\%$5.6 \%(n=10)$. Accuracy was assured by analyzing four samples of serum from the Trace Elements External Quality Assessment Scheme (University of Surrey, Guildford, Surrey, UK) and the following certified reference materials: Seronorm Serum JL4409 (Nycomed, Norway), which had a mean concentration of 0.90 (standard deviation [SD] 0.04) $\mu \mathrm{mol} / \mathrm{L}$ after five determinations (certified mean $0.92 \mu \mathrm{mol} / \mathrm{L}$, range $0.84-1.00 \mu \mathrm{mol} / \mathrm{L}$ ), and Seronorm Serum NO0371, with a mean concentration of 1.76 (SD $0.04) \mu \mathrm{mol} / \mathrm{L}$ (certified mean $1.72 \mu \mathrm{mol} / \mathrm{L}$, range $1.61-1.83 \mu \mathrm{mol} / \mathrm{L})$. The detection limit was $<0.01 \mu \mathrm{mol} / \mathrm{L}$.

\section{Statistical analysis}

The normal distribution of the concentrations of selenium was confirmed with the KolmogorovSmirnov test $(Z=1.13, p=0.16)$.

To evaluate whether preterm birth was related to maternal selenium status, we used a $t$ test to compare the mean selenium concentrations between the term and preterm groups. When we examined the effect of different cut-offs for selenium concentration on the percentage of preterm births, significant effects up to the 25th percentile 
could be seen. We therefore divided the women into quartiles according to serum selenium concentration. We did a series of univariable logistic regression analyses with overall preterm birth as the dependent variable and selenium concentration at 12 weeks' gestation as the independent variable. Finally, adjusted odds ratios (ORs) and 95\% confidence intervals (CIs) were calculated for selenium in relation to preterm birth by entering several risk factors into multiple logistic regression analyses. These risk factors included demographic characteristics (age, income, marital status and level of education), life-style factors (smoking status, consumption of alcohol and body mass index) and obstetric history (previous miscarriage, parity and diastolic pressure $>90$ $\mathrm{mm} \mathrm{Hg}$ at 12 weeks). ${ }^{1,1,19}$ To investigate the effect of selenium on preterm birth independent of the occurrence of preeclampsia, preeclampsia was entered into the regression model as a covariate.

\section{Results}

Of the 1129 women, $60(5.3 \%)$ had preterm births, 50 of which occurred between 33 and 37 weeks' gestation and 10 of which occurred before 33 weeks' gestation.

The demographic and lifestyle characteristics, obstetric histories and birth outcomes of the women who participated in the study are shown in Table 1. Significantly more primiparous than multiparous women had a preterm birth. Moreover, preterm birth occurred significantly more often among women who had preeclampsia. The mean serum selenium concentration was 1.01 (SD 0.13) $\mu \mathrm{mol} / \mathrm{L}$ for the group as a whole, 1.02 (SD 0.13) $\mu \mathrm{mol} / \mathrm{L}$ for the 1069 women with a term delivery and 0.96 (SD 0.14) $\mu \mathrm{mol} / \mathrm{L}$ for the 60 women with a preterm delivery (two-tailed $t=2.9, p=0.003)$. Women were grouped into quartiles using serum selenium concentration at 12 weeks' gestation: quartile $1<0.92 \mu \mathrm{mol} / \mathrm{L}$ $(n=288)$; quartile $2=0.92-1.01 \mu \mathrm{mol} / \mathrm{L}(n=280)$; quartile $3=1.02-1.10 \mu \mathrm{mol} / \mathrm{L}(n=283)$; and quartile $4>1.10 \mu \mathrm{mol} / \mathrm{L}(n=278)$. The proportion of women who delivered prematurely differed significantly by quartile, with corresponding percentages of $8.3 \%, 5.4 \%, 3.8 \%$ and $3.5 \%$ $\left(\chi^{2}=8.0,3\right.$ degrees of freedom [df], $\left.p=0.04\right)$.

Table 2 shows the different subcategories of preterm birth with the corresponding mean gestational age at delivery and the mean selenium concentration at 12 weeks' gestation. Preterm premature rupture of the membranes was the largest subcategory and accounted for $35 \%$ of the preterm births. There were 24 preterm births (8.3\%) among the 288 women in the lowest quartile of serum selenium. There were 36 preterm
Table 1: Characteristics of the 1129 pregnant women for whom complete data on birth outcomes were available

\begin{tabular}{|c|c|c|c|}
\hline \multirow[b]{2}{*}{ Characteristic } & \multicolumn{3}{|c|}{ Birth outcome, no. (\%) of women* } \\
\hline & $\begin{array}{c}\text { Term } \\
n=1069\end{array}$ & $\begin{array}{l}\text { Preterm } \\
n=60\end{array}$ & $p$ value \\
\hline Age, yr, mean (SD) & $30.5(3.6)$ & $29.9(3.1)$ & $0.160 \dagger$ \\
\hline Primiparous & 491 (46) & $43(72)$ & \\
\hline Multiparous & $578 \quad(54)$ & $17(28)$ & $<0.001 \ddagger$ \\
\hline 1 child & $456 \quad(43)$ & $12(20)$ & $0.410 \neq$ \\
\hline 2 children & $109(10)$ & $2 \quad(3)$ & $0.460 \ddagger$ \\
\hline$\geq 3$ children & $13 \quad(1)$ & $3 \quad(5)$ & $0.009 \neq$ \\
\hline With a partner & 1048 (98) & 57 (96) & \\
\hline Single & $21 \quad(2)$ & 3 (4) & $0.110 \ddagger$ \\
\hline \multicolumn{4}{|l|}{ Level of education } \\
\hline Low & $84 \quad(8)$ & $7(12)$ & $0.290 \ddagger$ \\
\hline Middle & $608(57)$ & $37(62)$ & $0.470 \ddagger$ \\
\hline College or pre-university & $299(28)$ & $12(20)$ & $0.180 \ddagger$ \\
\hline University & $78 \quad(7)$ & $4 \quad(7)$ & $0.850 \ddagger$ \\
\hline \multicolumn{4}{|l|}{ Monthly income, US\$ } \\
\hline$<1500$ & $63 \quad(6)$ & $7(12)$ & $0.770 \ddagger$ \\
\hline $1500-2000$ & $142(13)$ & $11(18)$ & $0.260 \ddagger$ \\
\hline $2000-3000$ & $546(51)$ & $28(47)$ & $0.500 \ddagger$ \\
\hline$>3000$ & $318(30)$ & $14(23)$ & $0.290 \ddagger$ \\
\hline \multicolumn{4}{|l|}{ Smoking habit } \\
\hline Never & $590(55)$ & $33(55)$ & $0.790 \ddagger$ \\
\hline Stopped earlier in life & $257(24)$ & $11(18)$ & $0.310 \ddagger$ \\
\hline Stopped before pregnancy & $94 \quad(9)$ & $7(12)$ & $0.450 \ddagger$ \\
\hline$<10$ cigarettes $/ \mathrm{d}$ & $109(10)$ & $7(12)$ & $0.830 \ddagger$ \\
\hline 10-20 cigarettes/d & $19 \quad(2)$ & $2(3)$ & $0.380 \neq$ \\
\hline \multicolumn{4}{|l|}{ Consumption of alcohol } \\
\hline Never & $342(32)$ & $21(35)$ & $0.660 \ddagger$ \\
\hline Stopped before pregnancy & $588(55)$ & $35(59)$ & $0.590 \ddagger$ \\
\hline$\leq 2$ units/wk & $107(10)$ & $2 \quad(3)$ & $0.110 \ddagger$ \\
\hline$>2$ units/wk & $32 \quad(3)$ & $2 \quad(3)$ & $0.880 \ddagger$ \\
\hline \multicolumn{4}{|l|}{ Obstetric features } \\
\hline Previous miscarriage & $190(18)$ & $13(22)$ & $0.440 \ddagger$ \\
\hline $\begin{array}{l}\text { Diastolic BP at } 12 \mathrm{wk}, \mathrm{mm} \mathrm{Hg} \text {, } \\
\text { mean (SD) }\end{array}$ & $69(8.7)$ & $69(8.1)$ & $0.980 \dagger$ \\
\hline $\begin{array}{l}\text { Diastolic BP at } 24 \text { wk, mm Hg, } \\
\text { mean (SD) }\end{array}$ & $66(7.7)$ & $67(7.3)$ & $0.990 \dagger$ \\
\hline \multicolumn{4}{|l|}{ No. with diastolic BP $>90 \mathrm{~mm} \mathrm{Hg}$} \\
\hline at $12 \mathrm{wk}$ & $19 \quad(2)$ & $1 \quad(2)$ & $0.950 \ddagger$ \\
\hline at $24 \mathrm{wk}$ & $(1)$ & $1 \quad(2)$ & $0.360 \ddagger$ \\
\hline $\begin{array}{l}\text { No. of women referred because } \\
\text { of preeclampsia }\end{array}$ & $60 \quad(6)$ & $13(22)$ & $<0.001 \ddagger$ \\
\hline $\begin{array}{l}\text { Gestational age at delivery, wk, } \\
\text { mean (range) }\end{array}$ & $\begin{array}{c}39.6 \\
(37.0-42.6)\end{array}$ & $\begin{array}{c}34.6 \\
(26.1-36.6)\end{array}$ & $<0.001 \dagger$ \\
\hline Birth weight, g, mean (SD) & $3523(485)$ & $2469(624)$ & $<0.001 \dagger$ \\
\hline Placental weight, g, mean (SD) & $622(128)$ & $567(152)$ & $0.034 \dagger$ \\
\hline $\begin{array}{l}\text { Serum selenium at } 12 \mathrm{wk}, \mu \mathrm{mol} / \mathrm{L} \text {, } \\
\text { mean (SD) }\end{array}$ & $1.02(0.13)$ & $0.96(0.14)$ & $0.003+$ \\
\hline $\begin{array}{l}\text { Note: } \mathrm{BP}=\text { blood pressure, } \mathrm{SD}=\text { standard } \\
* \text { Unless otherwise stated. } \\
+t \text { test. } \\
\neq \chi^{2} \text { test. }\end{array}$ & & & \\
\hline
\end{tabular}


births among the 841 women $(4.3 \%)$ in the upper three quartiles of serum selenium $\left(\chi^{2}=7.0,1 \mathrm{df}\right.$, $p=0.008$ ).

The results of several single logistic regression analyses that related overall risk of preterm birth to selenium status showed that women in the lowest quartile of serum selenium at 12 weeks' gestation had twice the risk of preterm birth as the women in the higher quartiles (OR 2.0, 95\% CI 1.19-3.47).

In the multivariable logistic regression analysis, a low serum selenium concentration was independently related to preterm birth (OR 2.18, 95\% CI $1.25-3.77$ ), as were primiparity (OR $2.99,95 \%$ CI $1.59-5.62)$ and preeclampsia (OR $3.19,95 \%$ CI 1.47-6.91) (Table 3).

\section{Interpretation}

The overall incidence of preterm birth in our study $(5.3 \%)$ is consistent with the rates reported in the literature. ${ }^{1}$ Of the demographic, obstetric and lifestyle characteristics that have been previously associated with increased odds of preterm birth, ${ }^{1,18,19}$ only primiparity showed a significant association in our study. Because only a few women in our study smoked or consumed more than two units of alcohol each week, it is not surprising that these factors were not significant in our analysis. Body mass index was not significantly related to preterm birth. This may have been because the women in our sample had a relatively favourable mean body mass index of 25 (SD 4.7) $\mathrm{kg} / \mathrm{m}^{2}$. Other independent factors that have previously been associated with preterm birth, such as non-white race, type 1 diabetes and multiple-gestation pregnancy, were exclusion criteria in our study.
In addition to primiparity, having preeclampsia and being in the lowest quartile of selenium concentration at 12 weeks' gestation were significantly associated with increased odds of preterm birth.

Although previous studies have linked low concentrations of selenium and the selenoproteins, glutathione peroxidase and thioredoxin reductase, in the plasma and placenta to gestational hypertension or preeclampsia, ${ }^{12,20-23}$ both of which are conditions associated with preterm birth, ${ }^{1}$ we found that selenium status during early gestation in healthy pregnant women was related to preterm birth and that this association was independent of the mother having preeclampsia.

Previous studies have shown that the Dutch population is marginally deficient in selenium. ${ }^{16}$ Comparably low concentrations are also found in the United Kingdom. ${ }^{12}$ The reported daily intake of selenium in the Netherlands $(58.7 \mu \mathrm{g})$ is probably inadequate for the synthesis of selenoprotein $\mathrm{P},{ }^{16}$ the carrier of selenium in the plasma. ${ }^{24}$

Selenium (likely in the form of selenoproteins or selenoenzymes) is involved in several pathways that have been implicated in preterm birth, in preterm premature rupture of the membranes and in preeclampsia. These pathways include the body's response to infection, the inflammatory response, placentation, placental ischemia-reperfusion, oxidative stress, the generation of antithyroid antibodies and premature degradation of the extracellular matrix of fetal membranes. ${ }^{1,3,5,25}$

Selenium is required for the body's immune response, ${ }^{6}$ so low concentrations in either the mother or the fetus can increase the risk of infection, a major cause of preterm birth. ${ }^{1}$ Inflamma-

\begin{tabular}{|c|c|c|c|}
\hline Cause of preterm birth & $\begin{array}{l}\text { No. (\%) of } \\
\text { births }\end{array}$ & $\begin{array}{l}\text { Gestational age at } \\
\text { delivery, wk, mean } \\
\text { (SD; range) }\end{array}$ & $\begin{array}{c}\text { Serum selenium } \\
\text { concentration, } \mu \mathrm{mol} / \mathrm{L}, \\
\text { mean (SD) }\end{array}$ \\
\hline PPROM & $21(35)$ & $35.6(1.2 ; 31.2-36.6)$ & $0.94(0.13)$ \\
\hline \multicolumn{4}{|l|}{ latrogenic } \\
\hline Preeclampsia & $13(22)$ & $34.1(1.8 ; 32.6-36.6)$ & $0.93(0.12)$ \\
\hline $\begin{array}{l}\text { Pregnancy-induced } \\
\text { hypertension }\end{array}$ & $2(3)$ & $36.2(0.2 ; 36.1-36.4)$ & $0.88(0.07)$ \\
\hline Miscellaneous & $8(13)$ & $34.6(1.2 ; 32.5-36.6)$ & $0.98(0.09)$ \\
\hline \multicolumn{4}{|l|}{ Idiopathic (spontaneous) } \\
\hline $\begin{array}{l}\text { Preterm uterine } \\
\text { contractions }\end{array}$ & $13(22)$ & $32.6(3.3 ; 26.1-36.6)$ & $1.00(0.11)$ \\
\hline Antepartum hemorrhage & $3(5)$ & $35.6(0.8 ; 35.1-36.5)$ & $1.06(0.11)$ \\
\hline
\end{tabular}


tion may be an underlying factor in many of the pathways implicated in preterm birth. Genetic polymorphisms that lead to an increase in the magnitude or duration of the inflammatory response have been associated with an increased risk of preterm birth, whereas those that lead to a decrease in the inflammatory response have been associated with lower risk. ${ }^{26}$ Previous studies have described the various roles that selenium plays in attenuating the excessive inflammatory response associated with adverse pregnancy outcomes. ${ }^{7,8,27-32}$

The selenoprotein, thioredoxin reductase, contributes to the upregulation of heme oxygenase-1 during inflammation and periods of oxidative stress. ${ }^{33-36}$ Heme oxygenase- 1 and its products (carbon monoxide, biliverdin and ferrous ions $\left.\left[\mathrm{Fe}^{2+}\right]\right)$ are vitally important for successful placentation, maintenance of uterine quiescence, regulation of hemodynamic control within the uterus and placenta, protection against ischemiareperfusion injury, protection against preeclampsia, regulation of the apoptotic and inflammatory cascades in trophoblast cells and for increased vasodilatory (carbon monoxide), anti-inflammatory (bilirubin and carbon monoxide), and antioxidant (biliverdin and bilirubin) effects. ${ }^{37-39}$

In addition, selenoenzymes, such as the glutathione peroxidases, are able to reduce the oxidative stress resulting both from the underdevelopment of the uteroplacental circulation and from placental ischemia-reperfusion by converting lipid hydroperoxides to harmless alcohols while selenoprotein $\mathrm{P}$ scavenges peroxynitrite. ${ }^{31}$ Selenium species have also been shown to decrease the ratio of matrix metalloproteinases to tissue inhibitors of the matrix metalloproteinases. ${ }^{40}$ This ability may potentially reduce the risk of fetal membrane rupture, which is one of the features associated with preterm birth. ${ }^{25}$

\section{Limitations}

The strengths of our study are its prospective design and careful recording of obstetric complications by a single researcher who was blind to the selenium status of the participants. Unfortunately, no data were available on whether the women had cervicovaginal or intrauterine infections during pregnancy, both of which are important determinants of preterm premature rupture of the membranes. The mean term of women with preterm premature rupture of the membranes in our study was relatively long, but infection is generally believed to be an important cause of very preterm birth. ${ }^{41}$ Our data are most relevant to women with a relatively low selenium status. Once the serum concentration of selenium surpasses a range of $1.02-1.10 \mu \mathrm{mol} / \mathrm{L}$, its effect on the odds of preterm birth appears to be attenuated.

We did not consider other variables such as a previous history of preterm birth or a recent delivery. Had we included those variables, we would have had to do a separate analysis for multiparous women, which would have given us only 17 preterm births and little statistical power.

We were further limited by only having enough funding to measure the selenium concentration at a single point during pregnancy. We were unable to measure plasma concentrations of glutathione peroxidase, selenoprotein $\mathrm{P}$ or heme oxygenase for financial reasons. However, several studies have shown that, in healthy pregnant women, plasma concentrations of selenium decrease linearly as pregnancy progresses, so measurement at 12 weeks' gestation is likely to be a good representation of subsequent values. ${ }^{13}$ We chose to measure selenium during early gestation to increase our chances of seeing any early involvement of selenium in the cause of preterm birth or another adverse outcome. Measurements at a later stage of pregnancy could be confounded by the adverse outcome itself (e.g., a lack of expansion of plasma volume could show up as a higher selenium concentration). ${ }^{42}$

Although we have shown that preterm birth was significantly associated with low selenium status at 12 weeks' gestation and have postulated credible mechanisms as to the reason for this association, we have not shown that a low selenium status is the cause of preterm birth. The association between selenium and preterm birth may be driven by inflammation. The plasma con-

Table 3: Results of multivariable logistic regression analysis of factors associated with increased risk of preterm birth

\begin{tabular}{|c|c|}
\hline Factor & OR $(95 \% \mathrm{Cl})$ \\
\hline Maternal age (unit change per yr) & $1.02(0.94-1.10)$ \\
\hline Income < US\$1500/month & $2.34(0.77-4.68)$ \\
\hline Marital status $=$ single & $2.08(0.69-7.81)$ \\
\hline Low level of education & $1.01(0.49-2.05)$ \\
\hline Smoking & $1.09(0.63-2.37)$ \\
\hline Consumption of alcohol $>2$ units/wk & $0.62(0.24-1.79)$ \\
\hline BMI (unit change per $\mathrm{kg} / \mathrm{m}^{2}$ ) & $1.03(0.97-1.08)$ \\
\hline $\begin{array}{l}\text { Low selenium level ( }<25 \text { th percentile } \\
\text { at } 12 \mathrm{wk} \text { gestation) }\end{array}$ & $2.18(1.25-3.77)$ \\
\hline Primiparity & $2.99(1.59-5.62)$ \\
\hline Previous miscarriage & $1.52(0.78-2.99)$ \\
\hline $\begin{array}{l}\text { Diastolic pressure }>90 \mathrm{~mm} \mathrm{Hg} \text { at } \\
12 \text { wk gestation }\end{array}$ & $1.01(0.97-1.05)$ \\
\hline Preeclampsia & $3.19(1.47-6.91)$ \\
\hline
\end{tabular}


centration of selenium decreases in proportion to the magnitude of the inflammatory response, whereas the concentration of selenoprotein $\mathrm{P}$ in the plasma declines as inflammatory activity and cytokine production increase..$^{43}$ In the presence of inflammation or infection, this phenomenon may occur as early as 12 weeks' gestation in women who will subsequently have difficulties during their pregnancies that could result in preterm birth. A small randomized controlled trial in Iran showed a significant reduction in the incidence of premature rupture of the membranes with supplementation of selenium. ${ }^{11}$ Those results suggest that the link between selenium status and preterm birth we have observed in our study may be more than just an association.

\section{Conclusion}

This study shows that low serum selenium concentration during early gestation is associated with preterm birth and may be linked to preterm premature rupture of the membranes.

Future studies should include measurement of selenoenzymes and heme oxygenase- 1 to help clarify the mechanisms involved in preterm birth. Further research in this area is warranted because there may be implications for prevention and treatment, particularly in areas such as Europe where selenium status is relatively low.

\section{References}

1. Goldenberg RL, Culhane JF, Iams JD, et al. Epidemiology and causes of preterm birth. Lancet 2008;371:75-84.

2. Saigal S, Doyle LW. An overview of mortality and sequelae of preterm birth from infancy to adulthood. Lancet 2008;371:261-9.

3. Romero R, Espinoza J, Gonçalves LF, et al. Inflammation in preterm and term labour and delivery. Semin Fetal Neonatal Med 2006;11:317-26.

4. Rosenberg TJ, Garbers S, Lipkind H, et al. Maternal obesity and diabetes as risk factors for adverse pregnancy outcomes: differences among $4 \mathrm{racial} / \mathrm{ethnic}$ groups. Am J Public Health 2005 95:1545-51.

5. Cleary-Goldman J, Malone FD, Lambert-Messerlian G, et al. Maternal thyroid hypofunction and pregnancy outcome. Obstet Gynecol 2008;112:85-92.

6. Rayman MP. Food-chain selenium and human heath: emphasis on intake. Br J Nutr 2008;100:254-68.

7. Vunta H, Davis F, Palempalli UD, et al. The anti-inflammatory effects of selenium are mediated through 15-deoxy- $\Delta 12,14$ prostaglandin J2 in macrophages. J Biol Chem 2007;282: 17964-73.

8. Moses EK, Johnson MP, Tømmerdal L et al. Genetic association of preeclampsia to the inflammatory response gene SEPS1. Am J Obstet Gynecol 2008;198:336.e1-5.

9. Negro R, Greco G, Mangieri T, et al. The influence of selenium supplementation on postpartum thyroid status in pregnant women with thyroid peroxidase autoantibodies. J Clin Endocrinol Metab 2007;92:1263-8.

10. Barrington JW, Lindsay P, James D, et al. Selenium deficiency and miscarriage: A possible link? Br J Obstet Gynaecol 1996; 103:130-2.

11. Tara F, Rayman MP, Boskabadi H, et al. Selenium supplementation and premature (pre-labour) rupture of membranes: a randomised double-blind placebo-controlled trial. J Obstet Gynaecol 2010;30:30-4.

12. Rayman MP, Bode P, Redman CW. Low selenium status is associated with the occurrence of the pregnancy disease preeclampsia in women from the United Kingdom. Am J Obstet Gynecol 2003;189:1343-9.

13. Dobrzynski W, Trafikowska U, Trafikowska A, et al. Decreased selenium concentration in maternal and cord blood in preterm compared with term delivery. Analyst 1998;123:93-7.

14. Sievers E, Arpe T, Schleyerbach U, et al. Plasma selenium in preterm and term infants during the first 12 months of life. J Trace Elem Med Biol 2001;14:218-22.

15. Nassi N, Ponziani V, Becatti M, et al. Anti-oxidant enzymes and related elements in term and preterm newborns. Pediatr Int 2009;51:183-7.

16. van den Brandt PA, Goldbohm RA, van't Veer P, et al. Predictors of toenail selenium levels in men and women. Cancer Epidemiol Biomarkers Prev 1993;2:107-12.

17. Sieniawska CE, Mensikov R, Delves HT. Determination of total selenium in serum, whole blood and erythrocytes by ICP-MS. J Anal At Spectrom 1999;14:109-12.

18. Swingle HM, Colaizy TT, Zimmerman MB, et al. Abortion and the risk of subsequent preterm birth: a systematic review with meta-analyses. J Reprod Med 2009;54:95-108.

19. Langhoff-Roos J, Kesmodel U, Jacobsson B, et al. Spontaneous preterm delivery in primiparous women at low risk in Denmark: population based study. BMJ 2006;332:937-9.

20. Mistry HD, Wilson V, Ramsay MM, et al. Reduced selenium concentrations and glutathione peroxidase activity in preeclamptic pregnancies. Hypertension 2008;52:881-8.

21. Walsh SW, Wang Y. Deficient glutathione peroxidase activity in preeclampsia is associated with increased placental production of thromboxane and lipid peroxides. Am J Obstet Gynecol 1993; 169:1456-61.

22. Lu BY. Changes in selenium in patients with pregnancy-induced hypertension [article in Chinese]. Zhonghua Fu Chan Ke Za Zhi 1990;25:325-7, 382.

23. Han L, Zhou S. Selenium supplement in the prevention of pregnancy induced hypertension. Chin Med J (Engl) 1994;107: $870-1$

24. Xia Y, Hill KE, Byrne DW, et al. Effectiveness of selenium supplements in a low selenium area of China. Am J Clin Nutr 2005; 81:829-34.

25. Parry S, Strauss JF III. Premature rupture of the fetal membranes. N Engl J Med 1998;338:663-70.

26. Holst D, Garnier Y. Preterm birth and inflammation - the role of genetic polymorphisms. Eur J Obstet Gynecol Reprod Biol 2008;141:3-9.

27. Ricote M, Li AC, Willson TM, et al. The peroxisome proliferator-activated receptor-gamma is a negative regulator of macrophage activation. Nature 1998;391:79-82.

28. Touyz RM, Schiffrin EL. Peroxisome proliferator-activated receptors in vascular biology-molecular mechanisms and clinical implications. Vascul Pharmacol 2006;45:19-28.

29. Gao Y, Hannan NR, Wanyonyi S, et al. Activation of the selenoprotein SEPS1 gene expression by pro-inflammatory cytokines in HepG2 cells. Cytokine 2006;33:246-51.

30. Curran JE, Jowett JB, Elliott KS, et al. Genetic variation in selenoprotein S influences inflammatory response. Nat Genet 2005;37:1234-41.

31. Brigelius-Flohé R, Banning A, Schnurr K. Selenium-dependent enzymes in endothelial function. Antioxid Redox Signal 2003;5: 205-15.

32. Rayman MP. Selenium. In: Milner JA, Romagnolo DF, editors. Bioactive compounds and cancer. New York (NY): Humana Press/Springer; 2010. p. 411-48.

33. Trigona WL, Mullarky IK, Cao Y, et al. Thioredoxin reductase regulates the induction of haem oxygenase-1 expression in aortic endothelial cells. Biochem J 2006;394:207-16.

34. Ejima K, Layne MD, Carvajal IM, et al. Modulation of the thioredoxin system during inflammatory responses and its effect on heme oxygenase-1 expression. Antioxid Redox Signal 2002; 4:569-75.

35. Lee TS, Tsai HL, Chau LY. Induction of heme oxygenase-1 expression in murine macrophages is essential for the antiinflammatory effect of low dose 15-deoxy-delta-12,14prostaglandin J2. J Biol Chem 2003;278:19325-30.

36. Krönke G, Kadl A, Ikonomu E, et al. Expression of heme oxygenase-1 in human vascular cells is regulated by peroxisome proliferator-activated receptors. Arterioscler Thromb Vasc Biol 2007;27:1276-82.

37. Bainbridge SA, Smith GN. HO in pregnancy. Free Radic Biol Med 2005;38:979-88.

38. Ahmed A, Rahman M, Zhang X, et al. Induction of placental heme oxygenase- 1 is protective against TNFalpha-induced cytotoxicity and promotes vessel relaxation. Mol Med 2000;6:391-409.

39. Kirkby KA, Adin CA. Products of heme oxygenase and their potential therapeutic applications. Am J Physiol Renal Physiol 2006;290:F563-71.

40. Zeng H, Briske-Anderson M, Idso JP, et al. The selenium metabolite methylselenol inhibits the migration and invasion 
potential of HT1080 tumor cells. J Nutr 2006;136:1528-32.

41. Hagberg H, Mallard C, Jacobsson B. Role of cytokines in preterm labour and brain injury. BJOG 2005;112(Suppl 1):16-8.

42. Rayman MP, Abou-Shakra FR, Ward NI, et al. Comparison of selenium levels in pre-eclamptic and normal pregnancies. Biol Trace Elem Res 1996;55:9-20.

43. Hesse-Bähr K, Dreher I, Köhrle J. The influence of the cytokines Il-1beta and INFgamma on the expression of selenoproteins in the human hepatocarcinoma cell line HepG2. Biofactors 2000; 11:83-5.

Affiliations: From the Faculty of Health and Medical Sciences (Rayman) University of Surrey, Guildford, UK; the Department of Medical Health Psychology (Wijnen, Pop), Tilburg University, Warandelaan Tilburg, the Netherlands; the Department of Biomedical Engineering (Vader), University of Technology, Eindhoven, the Netherlands; and the Department of Clinical Health Psychology (Kooistra), University of Groningen, the Netherlands
Contributors: Margaret Rayman was responsible for securing financing for selenium measurement and overseeing the analysis of the data and had a major role in writing the paper. Victor Pop, Hennie Wijnen and Libbe Kooistra were responsible for the follow-up study and contributed to the analysis of the data and the writing of the paper. Huib Vader was responsible for the collection and storage of the blood samples and participated in the analysis and writing of the paper. All of the authors approved the final version of the manuscript submitted for publication.

Funding: Data collection for this study was made possible by a grant from the Dr. DeGrood Foundation. The selenium analysis was funded by Pharma Nord (Denmark).

Acknowledgement: The authors thank Dr. Christine Sieniawska at the Trace Metal Laboratory, Southampton General Hospital, Southampton, Hampshire, UK, for conducting the selenium measurements.

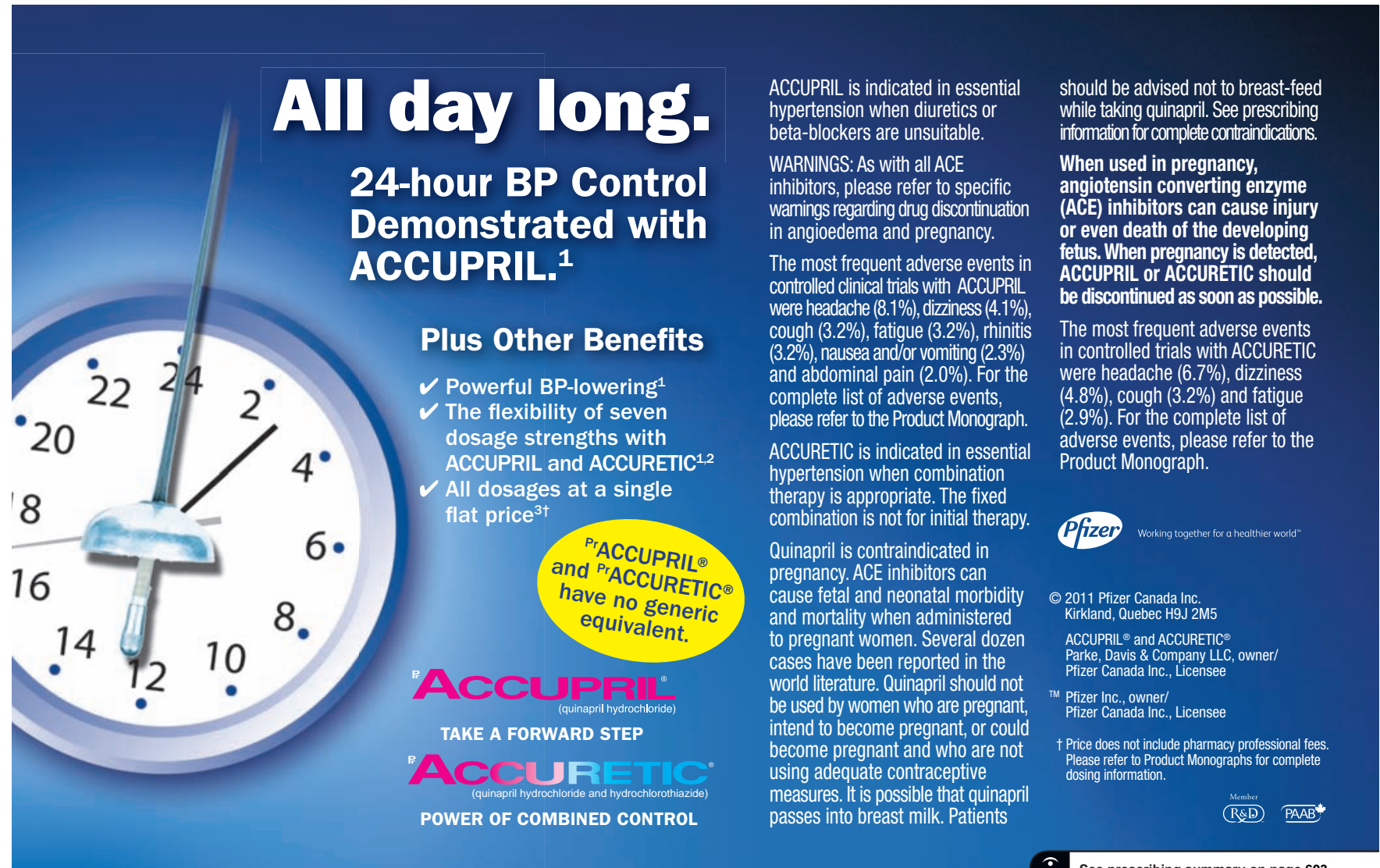

